\title{
Test Results and Nonlinear Analysis of RC T-beams Strengthened by Bonded Steel Plates
}

\author{
Wei Ren $^{1), *}$, Lesley H. Sneed ${ }^{2)}$, Yiting Gai $^{3)}$, and Xin Kang ${ }^{2)}$ \\ (Received December 22, 2013, Accepted January 28, 2015, Published online March 7, 2015)
}

\begin{abstract}
This paper describes the test results and nonlinear analysis of reinforced concrete T-beams strengthened by bonded steel plates under increasing static loading conditions. The first part of this paper discusses the flexural tests on five T-beams, including the test model design (based on similarity principles), test programs, and test procedure. The second part discusses the nonlinear numerical analysis of the strengthened beams, in which a concrete damage plasticity model and a cohesive behavior were adopted. The numerical analysis results are compared with experimental data and show good agreement. The area of bonded steel plate and the anchor bolt spacing were found to have an impact on the cracking load, yield load, and ultimate load. An increase in the area of steel plate and a reduction of the anchor spacing could significantly improve the cracking and ultimate loads and decrease the damage of the beam.
\end{abstract}

Keywords: bridge, cohesive behavior, concrete damage plasticity, cracking, finite element method, simulation.

\section{Introduction}

Bonding of a steel plate with epoxy adhesive on the tensile side of a reinforced concrete (RC) beam is one of the most accepted and widely used techniques for flexural strengthening. Over the past several decades, a large number of studies have been conducted by using this technique in different parts of the world (Adhikary and Mutsuyoshi 2002; Aprile et al. 2001; Oehlers et al. 1998). Despite its long history, a unified and rational design method for strengthening RC beams with bonded steel plates has not yet been established.

This paper presents the test results and numerical simulations of RC T-beam strengthened by bonded steel plates under increasing static loading conditions. The numerical simulations were conducted using a concrete damaged plasticity model and cohesive behavior to examine the possible failure mechanisms of the RC T-beam strengthened by bonded steel plates. The established model can be applied in future investigations to study different failure modes and

\footnotetext{
${ }^{1)}$ Key Laboratory of Bridge Detection Reinforcement Technology Ministry of Communications, Chang'an University, Xi'an 710075, Shaanxi, China.

*Corresponding Author; E-mail: rw20062@163.com

${ }^{2)}$ Department of Civil, Architectural \& Environmental

Engineering, Missouri University of Science and

Technology, Rolla, MO 65409, USA.

${ }^{3)}$ CCCC First Highway Consultants CO., LTD, Xi'an 710075, Shaanxi, China.
}

Copyright $@$ The Author(s) 2015. This article is published with open access at Springerlink.com the effects of various parameters on the strength and serviceability of steel-plate-strengthened RC beams. From the results, it is found that the simple model proposed can accurately predict the overall flexural behavior of strengthened beams up to ultimate state.

\section{Experiments}

\subsection{Specimen Preparation}

The test specimen design was based on a $16 \mathrm{~m}$ long RC Tbeam that was designed in accordance with the Chinese Highway Bridge Design Code (1974). The test specimen was designed based on similarity theory (Zhao et al. 2011). Similar constants are the geometric similarity constant $C_{l}=1 / 8$, the similarity constant of the elastic modulus $C_{E}=1$, and the similarity constant of Poisson's ratio $C_{n}=1$.

According to the reinforcement ratio similarity criterion $\pi_{1}, \rho_{m}=\rho_{p}$ is obtained, (i.e., the reinforcement ratio of the specimen is the same as that of the original beam). According to the flexural reinforcement ratio similarity criterion $\pi_{2}, \rho_{f m}=\rho_{f p}$ is obtained (i.e., the flexural reinforcement ratio obtained from the specimen is the same as that of the original beam). According to the loading ratio similarity criterion $\pi_{3}, P_{m}=P_{p} / 64$ (i.e., the load ratio obtained from the original beam is 64 times more than that of the test specimen). According to the unit weight similarity criterion $\pi_{4}, \gamma_{m}=8 \gamma_{p}$ (i.e., the load ratio obtained from the original beam is eight times more than that of the specimen).

Based on the above similarity analysis, the similarity parameters are given as: the similarity constant of the dead load $C_{w}=8$, and the similarity constant of the load $C_{F}=1 / 64$. 
Table 1 Geometric dimensions of the test specimen.

\begin{tabular}{c|c|c|c|c|c}
\hline & $l(\mathrm{~m})$ & $b(\mathrm{~m})$ & $h(\mathrm{~m})$ & $h_{f}(\mathrm{~m})$ & $b_{f}(\mathrm{~m})$ \\
\hline \hline Bridge beam & 16 & 1.6 & 1.1 & 0.11 & 0.18 \\
\hline Test specimen & 2 & 0.2 & 0.138 & 0.034 & 0.052 \\
\hline
\end{tabular}

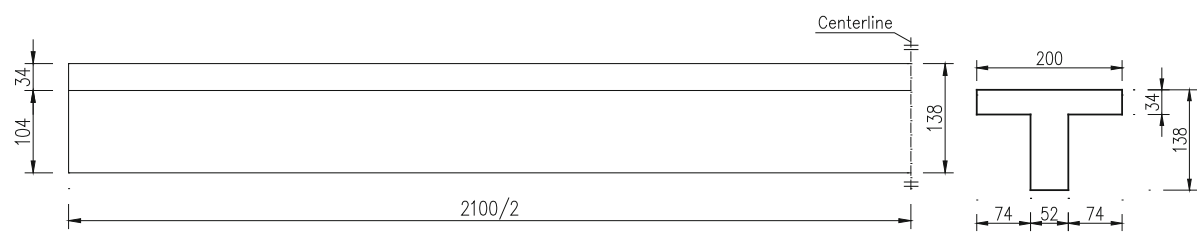

Fig. 1 Geometry of test specimen (dimensions in $\mathrm{mm}$ ).

Table 2 Measured material properties of steel bar, steel plate, and concrete.

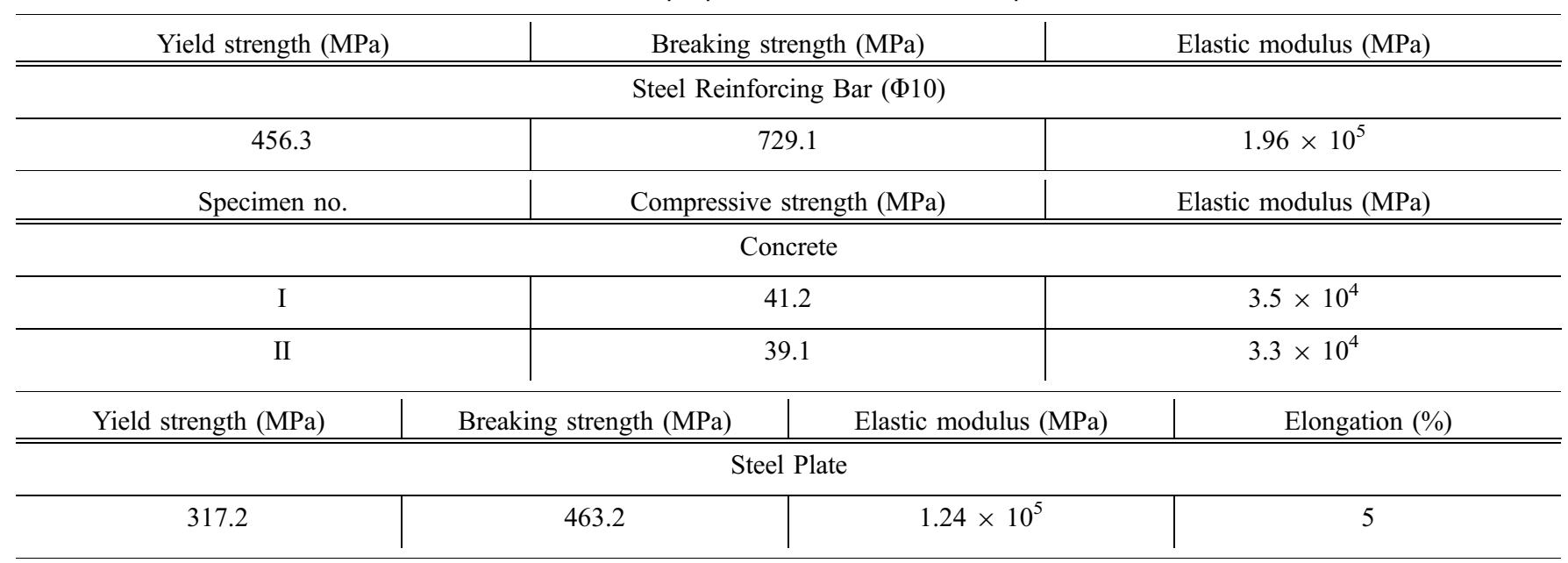

This test program consisted of testing five 2,100 $\mathrm{mm}$ (with a clear span of 2,000 mm) long RC T-beams. The geometric dimensions of the test specimen are shown in Table 1 and Fig. 1, which are determined according to the above-mentioned similarity constants.

\subsection{Material Properties}

The measured material properties of the steel reinforcing bars, the steel plate, and the concrete are shown in Table 2.

\subsection{Experimental Program}

A total of five beam specimens were tested. The beam dimensions are shown in Fig. 2. The beams were reinforced with steel plates bonded to the tension surface of the beam. All the beams were designed to fail in flexure, even after strengthening with steel plates, which made it possible to estimate the increase in flexural strength. Beam B-0 was kept as the reference (unstrengthened) beam, and other beams were bonded with steel plates. Each beam was reinforced with (2)-10 $\mathrm{mm}$ diameter bars in the flexural tension region, and $6 \mathrm{~mm}$ diameter stirrups spaced at $65 \mathrm{~mm}$ in the shear span and $100 \mathrm{~mm}$ in the region of pure flexure. Concrete was cast in two different batches and was designated as Type I and Type II (Table 2). One 1,800 $\mathrm{mm}$ long steel plate with a thickness of $2.0 \mathrm{~mm}$ was bonded to the bottom of each of the strengthened beams using epoxy adhesive. Two different plate widths, 21 and $42 \mathrm{~mm}$, were investigated. The properties of the steel reinforcing bars and the steel plates are summarized in Table 2. Before bonding the steel plates, the bottom surface of the beam was roughened by mechanical grinding and cleaned thoroughly with acetone. The bonding faces of the steel plates were also sand blasted and cleaned thoroughly with acetone. In order to attach the steel plates tightly to the beams, M8 bolts (diameter: $8 \mathrm{~mm}$, length: $40 \mathrm{~mm}$ ) were used, and within the region of pure flexure, two anchor spacings, $250 \mathrm{~mm}$ (Fig. 2a) and 1,000 mm (Fig. 2b), were investigated. Test specimen information is summarized in Table 3. The test results are presented in Sect. 4.

\subsection{Testing Procedure and Instrumentation}

All beam specimens were tested under four-point loading over a span of 2,000 $\mathrm{mm}$. Strains in the tensile reinforcing bars, the steel plates at different locations, and the concrete were recorded. Strain gauges were attached to the bottom edge and the mid-thickness of the steel plates at the middle of each shear span, as well as at the midspan in the longitudinal direction. Midspan displacement was measured by a linear variable displacement transducer (LVDT). The specimens were loaded under displacement control (Fig. 3). Crack initiation and propagation were monitored by visual inspection during testing, and crack patterns were marked. 


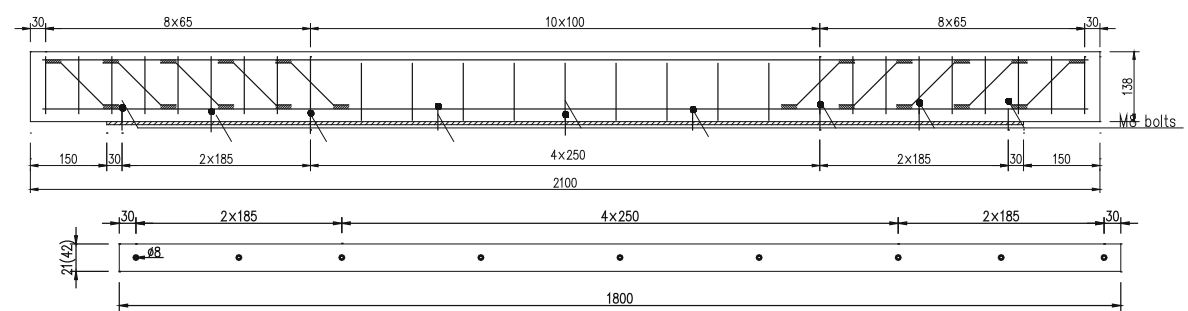

(a)
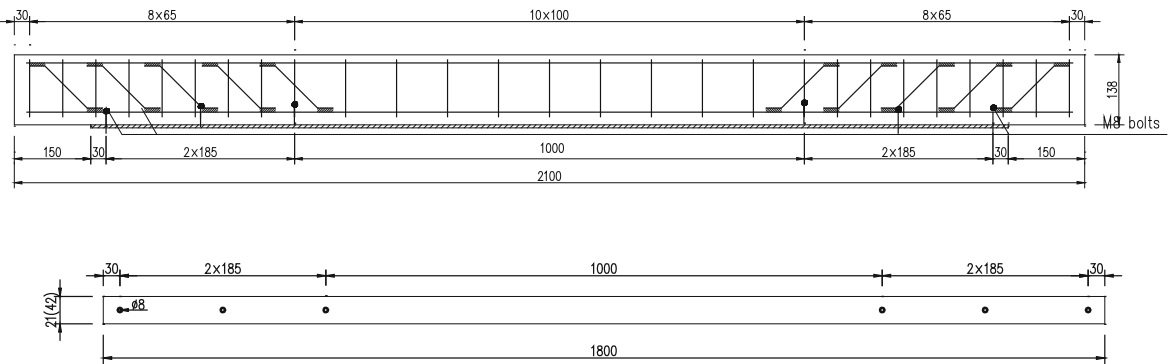

(b)

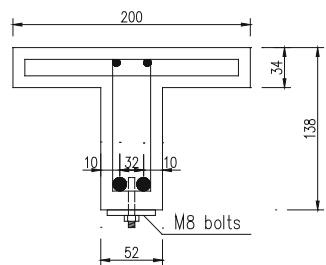

Fig. 2 Reinforcement details of the test specimens (dimensions in $\mathrm{mm}$ ).

Table 3 Test specimens.

\begin{tabular}{c|c|c|c}
\hline Specimen & Concrete type & Anchorage in pure bending region & Width of steel plate (mm) \\
\hline \hline B-0 & \multirow{2}{*}{ I } & - & - \\
\cline { 4 - 4 } B-2-2 & & Anchor at 2 points & 21 \\
\cline { 4 - 5 } B-5-2 & & Anchor at 5 points & 21 \\
\hline B-2-4 & \multirow{2}{*}{ II } & Anchor at 2 points & 42 \\
B-5-4 & & Anchor at 5 points & 42 \\
\hline
\end{tabular}

\section{Numerical Analysis}

\subsection{Concrete Damage Plasticity Model}

In numerical analysis of RC structures, the concrete constitutive relation has a significant impact on the results. The commercial program used in this study, ABAQUS, provides different types of concrete constitutive models including (1) a smeared crack model; (2) a discrete crack model; and (3) a damage plasticity model (ABAQUS 2010). The concrete damaged plasticity model, which can be used for modeling concrete and other quasi-brittle materials, was used in this study. This model combines the concepts of isotropic damaged elasticity with isotropic tensile and compressive plasticity to model the inelastic behavior of concrete. The model assumes scalar (isotropic) damage and can be used for both monotonic and cyclic loading conditions, and has better convergence. Elastic stiffness degradation from plastic straining in tension and compression were accounted in this study (Lubliner et al. 1989, Lee and Fenves 1998). Cicekli et al. (2007) and Qin et al. (2007) proved that damaged plasticity model could provide an effective method for modeling the concrete behavior in tension and compression.

The main parameters required in the concrete damage plasticity model, including the constitutive relationship of concrete, are defined by the user. The study described in this paper used the constitutive relation of concrete from the Chinese code GB 50010-2002 (China 2002), Guo (2001) and Xue et al. (2010).

The stress-strain relation for concrete under uniaxial tension equation is described using Fig. 4 and Eq. (1). Damage is assumed to occur only after the peak stress is reached.

$$
\begin{aligned}
& y=\frac{x}{\alpha_{t}(x-1)^{1.7}+x} \quad x \geq 1 \\
& \alpha_{t}=0.312 f_{t}^{2}
\end{aligned}
$$

where $\alpha_{t}$ is a decline curve parameter of concrete under uniaxial tension. $\alpha_{t}=0$ means the concrete constitutive 

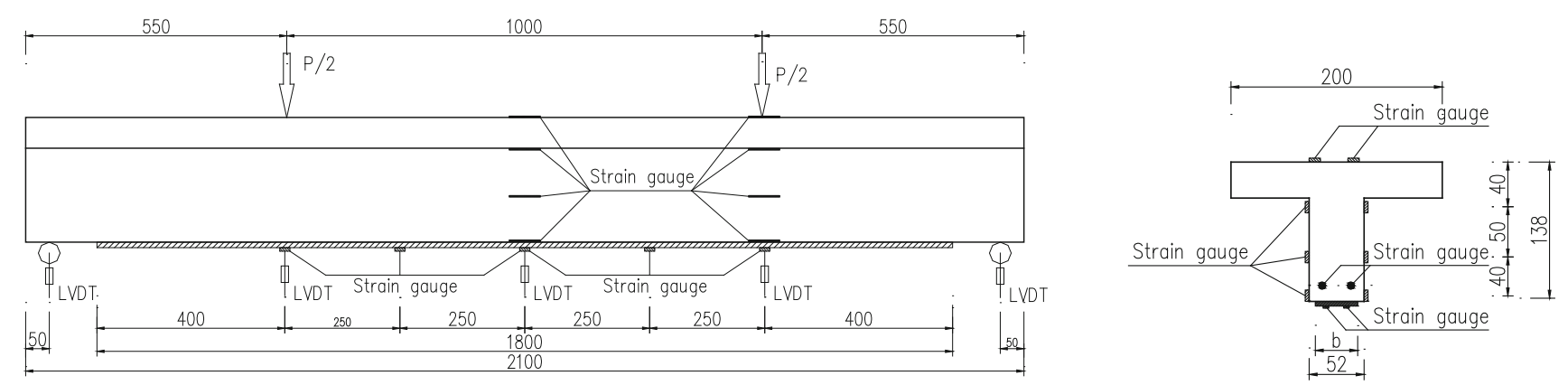

Fig. 3 Loading schematic (dimensions in $\mathrm{mm}$ ).

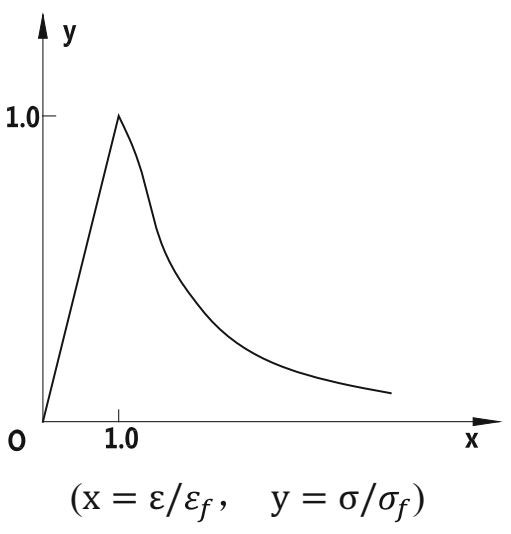

Fig. 4 Concrete uniaxial tensile stress-strain curve.

relation becomes a horizontal line (i.e., fully plastic) after peak load, while $\alpha_{t}=\infty$ means the concrete constitutive relation becomes a vertical line (i.e., fully brittle) after the peak load. $f_{t}$ is the tensile strength of concrete. Similarly the stress-strain relation for concrete under uniaxial compression can be described using Fig. 5 and Eq. (2).

$$
\begin{aligned}
& y=\frac{x}{\alpha_{d}(x-1)^{2}+x} \quad x \geq 1 \\
& \alpha_{d}=0.157 f_{c}^{0.785}-0.905
\end{aligned}
$$

where $\alpha_{d}$ is a decline curve parameter of concrete under uniaxial compression and $f_{c}$ is the compression strength of concrete. According to the conservation of energy, the complementary energy of damaged material is equal to that of the elastic material, as long as the stress is converted into an equivalent stress or the elasticity modulus is equal to an equivalent elastic modulus when the material is damaged.

$$
W_{0}^{e}=W_{d}^{e}
$$

In Eq. (3), $W_{0}^{e}$ is the complementary energy of undamaged material given in Eq. (4):

$$
W_{0}^{e}=\frac{\sigma^{2}}{2 E_{0}}
$$

And $W_{d}^{e}$ is the complementary energy of the damaged material given in Eq. (5):

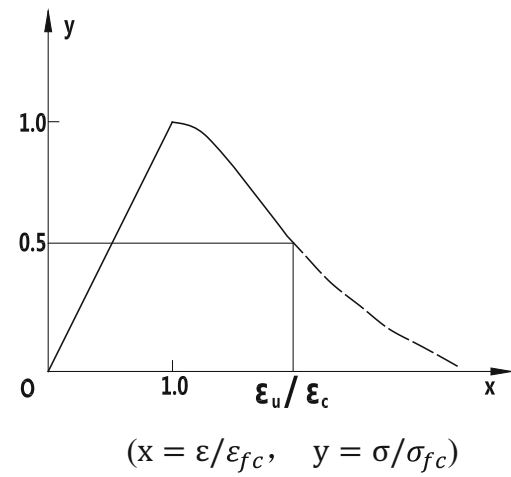

Fig. 5 Concrete uniaxial compressive stress-strain curve.

$$
W_{d}^{e}=\frac{\sigma^{\prime 2}}{2 E_{d}}
$$

where $E_{0}$ and $E_{d}$ are the undamaged and damaged elasticity moduli, respectively.

The equivalent stress is described using Cauchy's effective stress tensor in Eq. (6), in which D is the damage variable:

$$
\sigma^{\prime}=\frac{\sigma A}{A^{\prime}}=\sigma /(1-D)
$$

where $A$ and $A^{\prime}$ are the effective bearing area of undamaged and damaged section, respectively; and $\sigma$ and $\sigma^{\prime}$ are the effective stress of undamaged and damaged section. Combining Eqs. (3), (4), (5) and (1) results in Eqs. (7a) and (7b) below:

$$
\begin{aligned}
& E_{d}=E_{0}(1-D)^{2} \\
& \sigma=E_{0}(1-D)^{2} \varepsilon
\end{aligned}
$$

Adopting the principles above, the uniaxial tensile damage equation can be described in Eqs. (8a) and (8b):

$$
\begin{aligned}
& D=0 \quad x \leq 1 \\
& D=1-\sqrt{\frac{1}{\left[\alpha_{t}(x-1)^{1.7}+x\right]}} \quad x \geq 1
\end{aligned}
$$

Similarly, the uniaxial compressive damage equation is described in Eqs. (9a) and (9b): 
$D=0 \quad x \leq 1$

$D=1-\sqrt{\frac{1}{\left[\alpha_{d}(x-1)^{2}+x\right]}} \quad x \geq 1$

\subsection{Model Parameters}

(1) Dilation angle $\psi$ is a measurement of how much volume increase occurs when the material is sheared. For a Mohr-Coulomb material, dilation is an angle that generally varies between zero (non-associative flow rule) and the friction angle (associative flow rule). Tuo et al. (2008) recommended adopting $30^{\circ}$ for concrete material. By comparison with the experimental values, this paper takes a value of $38^{\circ}$.

(2) Flow potential eccentricity $\varepsilon$ is a small positive number that defines the rate at which the hyperbolic flow potential approaches its asymptote. This paper takes a value of 0.1 . The plastic-damage model assumes nonassociated potential flow; $\dot{\varepsilon}^{p l}=\dot{\lambda} \frac{\partial G(\bar{\sigma})}{\partial \bar{\sigma}}$. The flow potential $G$ chosen for this model is the DruckerPrager hyperbolic function:

$G=\sqrt{\left(\varepsilon \sigma_{t 0} \tan \psi\right)^{2}+\bar{q}^{2}}-\bar{p} \tan \psi$

where $\Psi$ is the dilation angle; $\sigma_{t 0}$ is the uniaxial tensile stress at failure; and $\varepsilon$ is a parameter, referred to the eccentricity, that defines the rate at which the function approaches to the asymptote (the flow potential tends to a straight line as the eccentricity tends to zero). This flow potential, which is continuous and smooth, ensures that the flow direction is defined uniquely.

(3) $\sigma_{b 0} / \sigma_{c 0}$ is the ratio of initial equibiaxial compressive yield stress to initial uniaxial compressive yield stress. This paper uses a value of 1.16. $\sigma_{b 0}$ and $\sigma_{c 0}$ are the equibiaxial compressive yield stress and initial uniaxial compressive yield stress, respectively.

(4) $K_{c}$ is the ratio of the second stress invariant on the tensile meridian, $q(T M)$, to the compressive meridian, $q(C M)$, at initial yield for any given value of the pressure invariant $P$ such that the maximum principal stress is negative, $\hat{\sigma}_{\max }<0$. It must satisfy the condition $0.5<K_{c}<1.0$. This paper takes a value of $2 / 3$.

(5) Viscosity parameter $\mu$ is used for the visco-plastic regularization of the concrete constitutive equations in ABAQUS/Standard analyses.

Material models exhibiting softening behavior and stiffness degradation often lead to severe convergence difficulties in implicit analysis programs. A common technique to overcome some of these convergence difficulties is the use of a viscoplastic regularization of the constitutive equations, which would lead to the consistent tangent stiffness of the softening material to become positive for sufficiently small time increments.

Using the viscoplastic regularization with a small value for the viscosity parameter (this paper takes a value of 0.0005 ) usually helps to improve the rate of convergence of the model in the softening regime and without compromising results. The lower the coefficient, the higher the calculation accuracy, but the calculation is more time consuming.

\subsection{Cohesive Behavior}

\subsubsection{Basic Principle}

Cohesive behavior describes the surface interaction property and is primarily intended for situations in which the interface thickness is negligibly small. It can be used to model delamination at interfaces in terms of traction versus separation. It assumes a linear elastic traction-separation law prior to damage and assumes that failure of the cohesive bond is characterized by progressive degradation of the cohesive stiffness, which is driven by a damage process.

There is no traction-separation model of steel plate-concrete bonded interfaces in the current literature, however, traction-separation models of FRP-concrete bonded interfaces are available in the literature, such as models by Neubauer and Rostasy (1999), Nakaba et al. (2001), Savoia et al. (2003), and Monti et al. (2003). Based on the results from Cicekli et al. (2007) and Fang et al. (2007),this paper uses the bilinear model by Monti et al. (2003) (Fig. 6).

The linear elastic traction-separation behavior is written in terms of an elastic constitutive matrix that relates the normal and shear stresses to the normal and shear separations across the interface. It can be written as:

$$
t=\left\{\begin{array}{c}
t_{n} \\
t_{s} \\
t_{t}
\end{array}\right\}=\left[\begin{array}{lll}
K_{n n} & K_{n s} & K_{n t} \\
K_{n s} & K_{s s} & K_{s t} \\
K_{n t} & K_{s t} & K_{t t}
\end{array}\right]\left\{\begin{array}{c}
\delta_{n} \\
\delta_{s} \\
\delta_{t}
\end{array}\right\}=K \delta
$$

where $t_{n}, t_{s}, t_{t}$ represent the normal and the two shear tractions nominal traction stress vectors. The corresponding separations are denoted by $\delta_{n}, \delta_{s}, \delta_{t}$.

Damage modeling allows simulating the degradation and eventual failure of the bond between two cohesive surfaces. The failure mechanism consists of two components: a damage initiation criterion and a damage evolution law. The initial response is assumed to be linear as discussed above. However, once a damage initiation criterion is met, damage can occur according to a user-defined damage evolution law. Damage initiation includes maximum and minimum stress criteria described below.

Maximum stress criterion:

$$
\max \left\{\frac{\left\langle t_{n}\right\rangle}{t_{n}^{0}}, \frac{t_{s}}{t_{s}^{0}}, \frac{t_{t}}{t_{t}^{0}}\right\}=1
$$

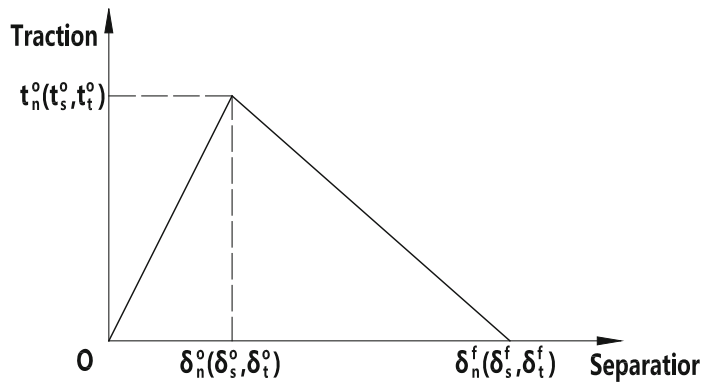

Fig. 6 Bilinear model. 
Maximum separation criterion:

$$
\max \left\{\frac{\left\langle\delta_{n}\right\rangle}{\delta_{n}^{0}}, \frac{\delta_{s}}{\delta_{s}^{0}}, \frac{\delta_{t}}{\delta_{t}^{0}}\right\}=1
$$

where $t_{n}^{0}, t_{s}^{0}$ and $t_{t}^{0}$ represent the peak values of the contact stress when the separation is either purely normal to the interface or purely in the first or the second shear direction, respectively. Likewise, $\delta_{n}^{0}, \delta_{s}^{0}$ and $\delta_{t}^{0}$ represent the peak values of the contact separation, when the separation is either purely along the contact normal or purely in the first or the second shear direction, respectively.

For the damage evolution law, a scalar damage variable, $D$, represents the overall damage at the contact point. $D$ initially has a value of 0 . If damage evolution is modeled, $D$ monotonically evolves from 0 to 1 upon further loading after the initiation of damage. The contact stress components are affected by the damage according to:

$$
\begin{aligned}
& t_{n}=\left\{\begin{array}{l}
(1-D) \bar{t}_{n}, \bar{t}_{n} \geq 0 \\
\bar{t}_{n}, \bar{t}_{n} \leq 0
\end{array}\right. \\
& t_{n}=(1-D) \bar{t}_{s} \\
& t_{t}=(1-D) \bar{t}_{t}
\end{aligned}
$$

where $\bar{t}_{n}, \bar{t}_{s}$ and $\bar{t}_{s}$ are the contact stress components predicted by the elastic traction-separation behavior for the current separations without damage.

\subsubsection{Basic Parameters}

Interfacial stress and separation relationship can be determined by the following:

$$
\left\{\begin{array}{cl}
\tau=\tau_{\max } \frac{\delta}{\delta_{0}} & \delta \leq \delta_{0} \\
\tau=\tau_{\max } \frac{\delta_{f}-\delta}{\delta_{f}-\delta_{0}} & \delta_{0}<\delta \leq \delta_{f} \\
\tau=0 & \delta>\delta_{f}
\end{array}\right.
$$

The peak values of the contact stress:

$$
\tau_{\max }=1.8 \beta_{w} f_{t}
$$

The separation corresponding to $\tau_{\max }$ is:

$$
\delta_{s}^{0}, \delta_{t}^{0}=2.5 \tau_{\max }\left(\frac{d_{a}}{E_{a}}+\frac{50}{E_{c}}\right)
$$

The ultimate separation is:

$$
\delta_{f}=0.33 \beta_{w}
$$

The width coefficient is:

$$
\beta_{w}=\sqrt{1.125 \frac{2-b_{f} / b_{c}}{1+b_{f} / 400}}
$$

where $E_{a}$ represents the cohesive modulus of elasticity, $\mathrm{MPa} ; E_{c}$ represents the concrete modulus of elasticity, $\mathrm{MPa}$; $f_{t}$ represents tensile strength of concrete, $\mathrm{MPa} ; d_{a}$ represents thickness of steel plate, $\mathrm{mm} ; b_{f}$ represents width of steel plate, $\mathrm{mm} ; b_{c}$ represents width of concrete, $\mathrm{mm}$.

The separation damage constitutive model is defined according to:

$$
D=\left\{\begin{array}{lr}
0 & 0<\delta \leq \delta_{0} \\
1-\tau_{\max } \frac{1}{\delta B} \frac{\delta_{f}-\delta}{\delta_{f}-\delta_{0}} & \delta_{0}<\delta \leq \delta_{f} \\
1 & \delta>\delta_{f}
\end{array}\right.
$$

\subsection{Proposed Model}

In order to accurately simulate the actual behavior of the RC T-beams investigated in this study, a description of the material, model configuration, boundary conditions, and loading are required. For the linear elastic behavior simulations, at least two material constants are required: Young's modulus $(E)$ and Poisson's ratio $(v)$. For nonlinear analysis, the steel and concrete uniaxial behaviors beyond the elastic range must be defined to simulate their behavior at higher stresses. The minimum input parameters required to define the concrete material are the uniaxial compression curve, the ratio of biaxial and uniaxial compressive strength, and the uniaxial tensile strength. The bond between the steel plate and concrete surface was model by cohesive behavior. The anchor was modeled by the node coupled method, where the nodes of the steel reinforcing bar and the steel plate were coupled.

\subsubsection{Symmetry}

Because the RC T-beams investigated had two axes of symmetry, it is possible to represent the full beam by modeling only one fourth of the beam (Fig. 7). This allowed for reduced analysis time.

\subsubsection{Finite Element Type and Mesh}

Different element types were evaluated to determine a suitable element type to simulate the behavior of the investigated beams. Because it was of interest to include the response of the concrete under tensile pressure, the concrete elements were modeled as solid elements, which were found to be more efficient both in modeling the behavior and clearly defining the boundaries of their elements. A fine mesh of three-dimensional eight-node solid elements C3D8 (Tuo et al. 2008) was used in this study. The final model contained 5,659 nonlinear concrete elements (C3D8R), 596 three-dimensional linear elastic truss elements (T3D2), and

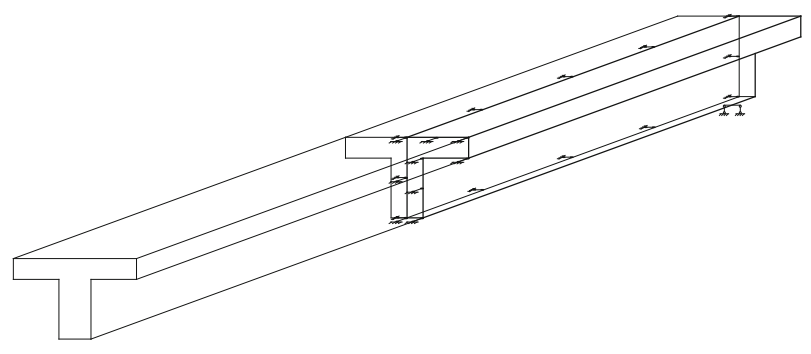

Fig. 7 Schematic drawing of one-fourth of the T-beam. 


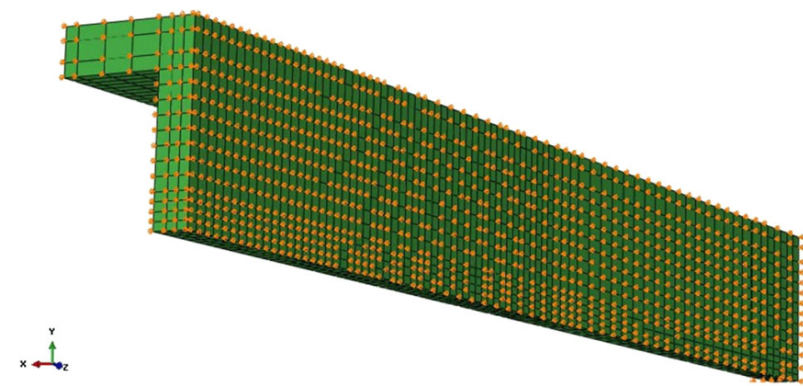

Fig. 8 FE model of one fourth of the T-beam.

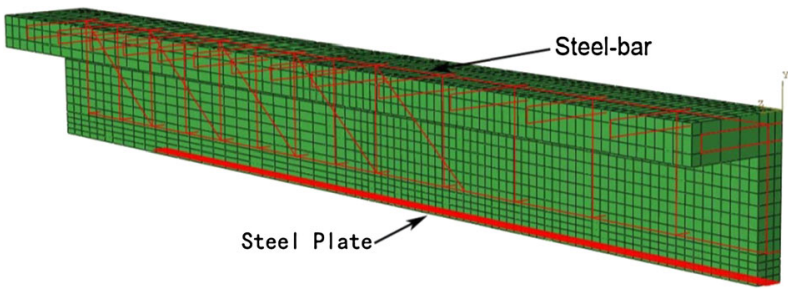

Fig. 9 Reinforcing bar was modeled as embedded regions.

560 shell elements (S4R). The maximum solid elements sizes were $21.3 \times 14 \times 20 \mathrm{~mm}$ at the flange, and the minimum were $10 \times 10 \times 10 \mathrm{~mm}$ at the web. A sketch of the finite element model is shown in Fig. 8.

\subsubsection{Embedded Elements}

This technique is often used to place embedded nodes at desired locations with the constraints on translational degrees-of-freedom on the embedded element by the host element. The rebar was modeled as embedded regions in the concrete in the interactive module, and assigning the concrete as the host (Fig. 9). Thus, the reinforcing bar elements had translations or rotations equal to those of the host elements surrounding them (i.e., perfect bond) (Garg and Abolmaali 2009).

\subsubsection{Boundary Constraints}

Due to symmetry, only a quarter of the panel was modeled as shown in Fig. 8. The nodes on the symmetry surfaces were prevented from displacement in $\mathrm{X}$ and $\mathrm{Y}$ directions, respectively. On the bearing point, only the degree of freedom in the $\mathrm{Z}$ direction was constrained.

\subsubsection{Loading Method}

Two loading methods are commonly used for numerical analysis: (1) application of the force $P$; or (2) application of the displacement $\delta$. In this study, the loading was applied by incrementally increasing the displacement. This loading method was selected for consistency with the experimental procedure in which the test specimens were loaded under displacement control, as well as for convergence issues. External loads were obtained from the reaction forces, and the peak (failure) load was obtained by plotting the $P-\delta$ response.

\subsubsection{Convergence}

When solving concrete problems, it is often difficult to obtain convergence. Especially after concrete cracks, strain energy is suddenly released, and the calculation becomes extremely unstable. Through repeated trials, these issues were resolved with the following considerations:

(1) Displacement loading was enforced. At the time of concrete cracking, the initial step was adjusted to 0.005 , and the automatic time step was adopted.

(2) Modifications were made to the constitutive equation by introducing the coefficient of viscosity. A high viscosity coefficient will make the structure "hard". Through repeated trials, a viscosity coefficient of 0.0005 was found to give better results.

(3) In concrete nonlinear finite element analysis, the solution is sometimes more important than the calculation accuracy. Therefore, the force and displacement convergence criteria are adjusted to make calculations carried out smoothly. Generally it takes $0.02 \sim 0.03$ load displacement tolerance. Through repeated trials, a value of 0.03 was found to give reasonable results (Jiang et al. 2005).

\section{Numerical Analysis and Discussion}

\subsection{Load-Deflection Relationship}

Figure 10a-e shows analytical and experimental loaddeflection curves of the five beam specimens. In these figures, indices I-III indicate the loading states. I indicates initiation of flexural cracking, II indicates the yielding of reinforcing bar and/or steel plate, and III indicates the maximum load.

The analytical results for beam B-0 (Fig. 10a) agree well with the experimental results. By comparing the reinforced $\mathrm{RC}$ beams shown in Fig. 10b-e, it is confirmed that the stiffness of the RC beam decreases sharply at points I and II due to opening of the flexural cracks and yielding of reinforcing bar and/or steel plate, respectively. After reinforcing bar yielding, the load-deflection curves are almost linear up to the maximum load point. At point III, the applied load decreases suddenly due to concrete crushing.

It can be seen from beam B-5-2 (Fig. 10c) that there is significant difference between analytical and experimental curves after point II. Experimental values of beam B-5-2 are obviously too small after point II by comparison with the other strengthened beams (Fig. 10b, d and e). The reason is that the steel plate was damaged in advance, which happened before the reinforcing bar yielding, because the anchoring holes at the loading point weakened the effective area of the steel plate. The numerical analysis did not consider the debilitating effects of the anchor hole on the steel plate and therefore predicts that beam B-5-2 fails in the sequence of yielding of reinforcing bar, yielding of steel plate, and then crushing of concrete.

These discussions suggest that the load-carrying capacity and failure behavior of $\mathrm{RC}$ beams reinforced in flexure with externally bonded steel plate can be simulated with good accuracy using the proposed numerical analysis method. 


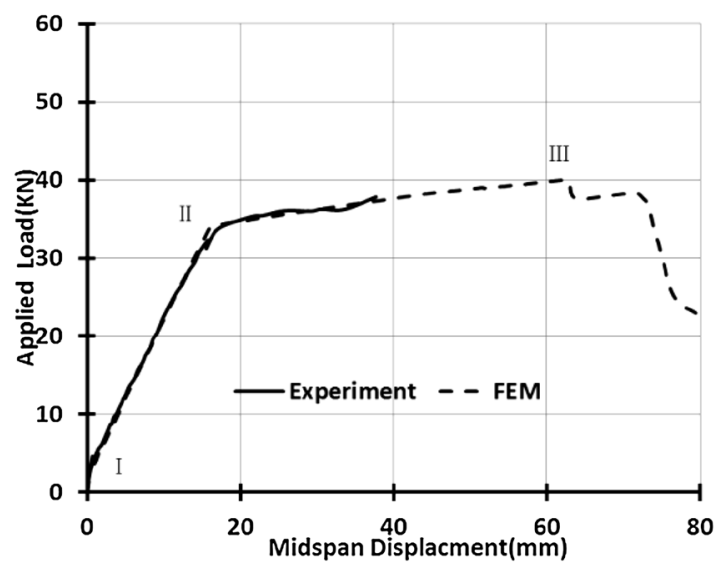

(a) B-0

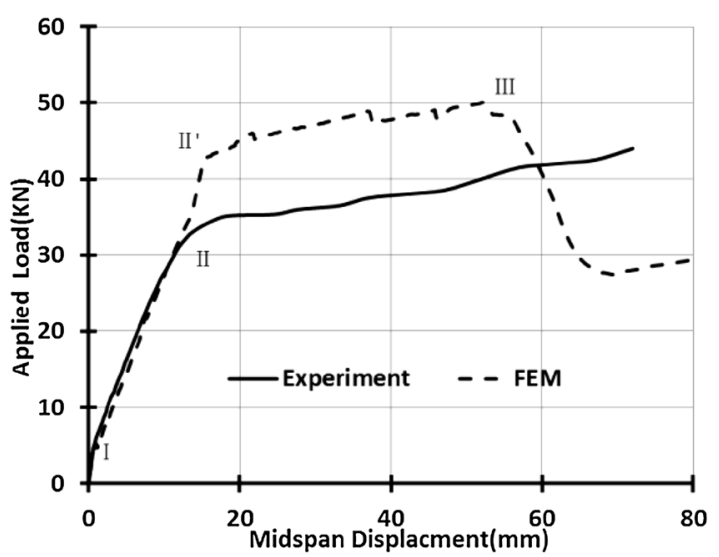

(c) B-5-2

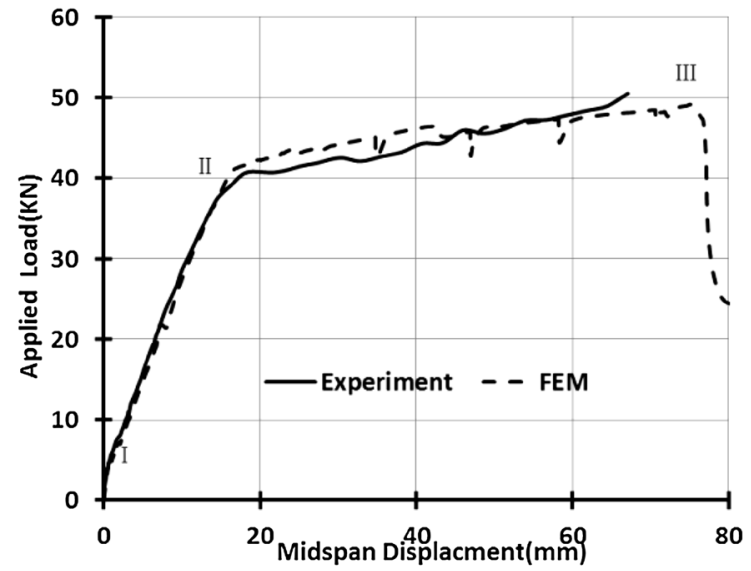

(b) B-2-2

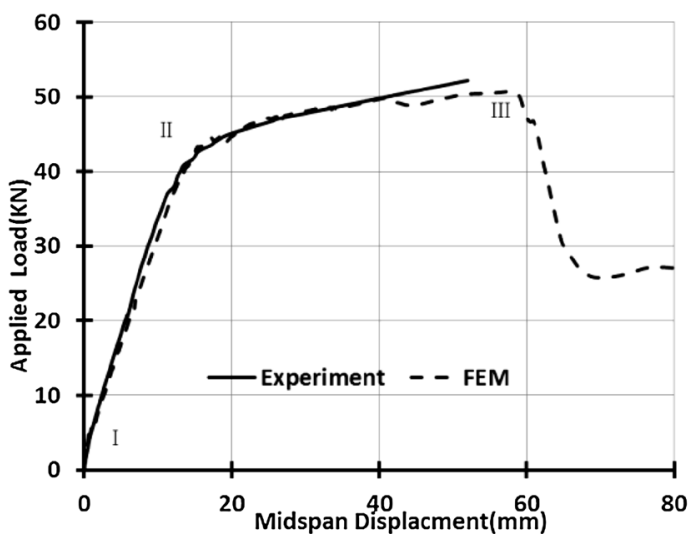

(d) B-2-4

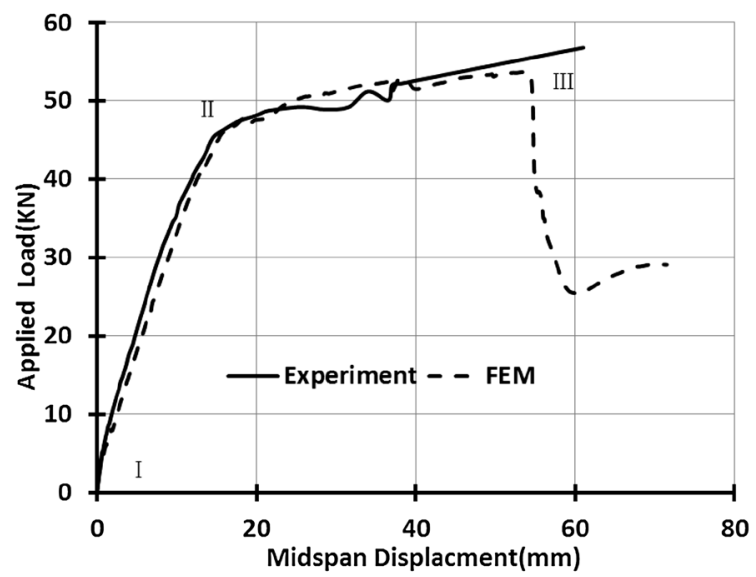

(e) B-5-4

Fig. 10 Comparison of analytical and experimental results-load-midspan displacement responses.

\subsection{Strain Distribution of Steel Plate}

Figure 11 compares the analytical and experimental strain distributions of the steel plate at the following loading stages: $30,35,40,45$, and $50 \mathrm{kN}$. In this figure, analytical results and experimental results are illustrated using the strains measured over the $1 / 2$ length of the span.

Comparisons for beams B-2-2, B-2-4, B-5-2, and B-5-4 show that analytical results agree roughly with the experimental results at each of the loading states.
Based on the observed analytical results, the strain of steel plate was found to increase suddenly at the section of concrete cracking (plastic strain section). This shows that the cohesive behavior can be used to simulate the stress transfer between concrete and steel effectively. It also can be seen that the strain in the steel plate and local concrete increases rapidly at the end of steel plate. This is consistent with the experimental observation.

In this research, the steel plate was bonded to the concrete by an epoxy adhesive and with mechanical anchors (i.e., bolts). Due to the existence of the bolts, the slip phenomenon 


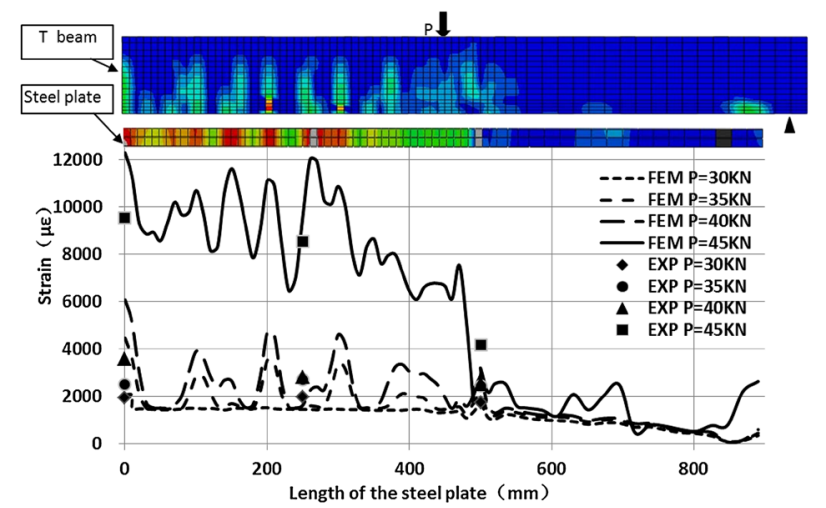

(a) B-2-2

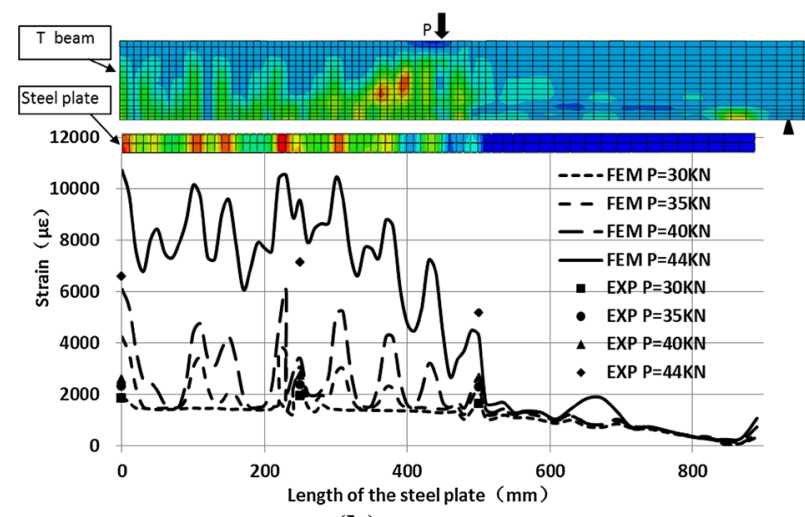

(b) B-5-2
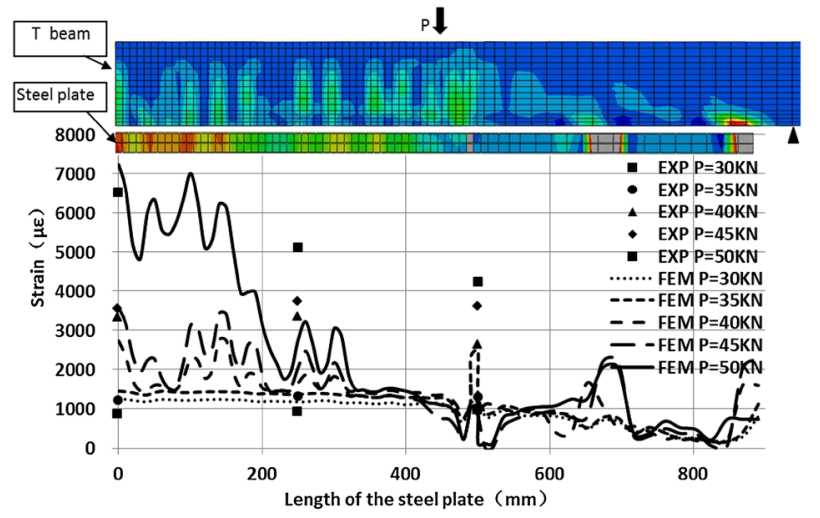

(c) B-2-4

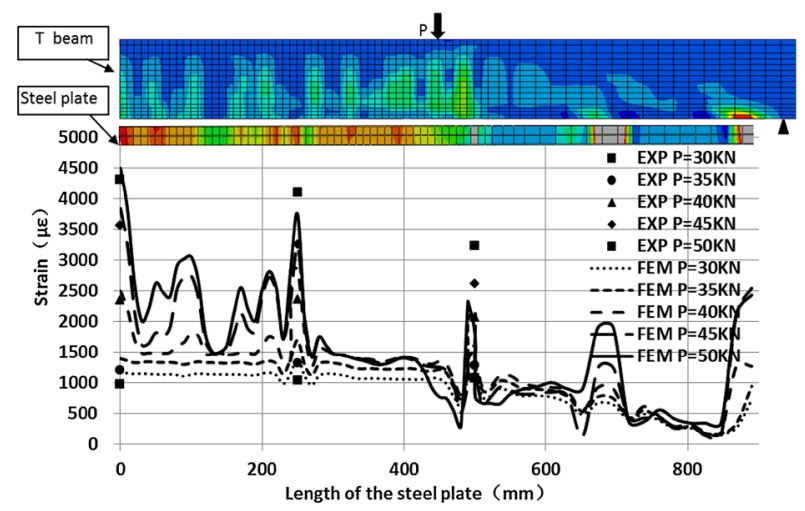

(d) B-5-4

Fig. 11 Comparison of analytical and experimental resultsstrain distribution of steel plate along the span.

between the concrete and steel plate was been minimized, thus there was a relatively small slip phenomenon between the bolts, which can be observed in Fig. 11.

\subsection{The Cracking Load, Yield Load and Failure Loads}

The failure load for the numerical analysis was defined as peak load in the $P-\delta$ curves. Table 4 compares the cracking load, yield load, and failure loads from the experiments with those from the numerical analysis, $P_{\text {Test }}$ and $P_{F E}$, respectively. With the exception of beam B-5-2, it can be observed that the correlation is quite good between the numerical results and the experimental data for the cracking load, yield load, and failure loads. The error is within $8.9 \%$ in cracking load, $7.7 \%$ in the yield load, and $9.7 \%$ in failure load.

It can be seen from Table 4 that a relatively large deviation between the experimental and numerical results was found for beam B-5-2. By comparing with the experimental observations, the reason could be attributed to the steel plate damage in advance which influenced the response before the yield load, because the anchor hole at the loading point weakened the effective area of the steel plate (as discussed previously).

\subsection{Failure Modes}

Figure 12 shows the destruction of the five beams. The failure modes of beams B-0, B-2-2, B-5-2, and B-5-4 were steel plate (rebar) yield/damage and concrete crushing, whereas the failure mode of beam B-2-4 was bolt failure as seen in Fig. 12d. Figures 13, 14 and 15 show the failure modes of the beams predicted by the proposed numerical model. Comparing with the experiment results, it is clearly seen that the proposed FEM model could accurately predict the failure modes and failure loads of the tested beams.

\section{Conclusions}

In this paper, nonlinear finite element analyses of RC Tbeams strengthened in flexure with externally bonded steel plates were performed. Based comparison of the experimental tests and numerical results, the following conclusions could be drawn:

(1) The concrete damaged plasticity model was found to accurately predict the concrete failure characteristics. Cohesive behavior method and the bilinear tractionseparation model were used to simulate the loadtransferring mechanism between the steel plate and concrete, and satisfactory results were achieved.

(2) The use of bonded steel plate and anchor bolts had a significant impact on the cracking load, yield load, and ultimate load. Increasing the width of steel plate and reducing the spacing of anchor bolts could significantly improve the cracking load, yield load, and ultimate load. However, the cracking load and ultimate load increase was not proportional to the area of steel plate.

(3) Increasing the width of steel plate and decreasing the anchor bolt spacing resulted in change of failure mode from steel yielding to premature failure attributed to the anchor bolt hole. 
Table 4 Comparison of cracking load, yield load, and failure loads.

\begin{tabular}{c|c|c|c|c|c|c|c|c|c}
\hline \multirow{2}{*}{ Specimen } & \multicolumn{3}{|c|}{ Cracking load $(\mathrm{kN})$} & \multicolumn{3}{c|}{ Yield load $(\mathrm{kN})$} & \multicolumn{3}{c}{ Failure load $(\mathrm{kN})$} \\
\cline { 2 - 11 } & $P_{\text {Test }}$ & $P_{F E}$ & $P_{F E} / P_{\text {Test }}(\%)$ & $P_{\text {Test }}$ & $P_{F E}$ & $P_{F E} / P_{\text {Test }}(\%)$ & $P_{\text {Test }}$ & $P_{F E}$ & $P_{F E} / P_{\text {Test }}(\%)$ \\
\hline \hline B-0 & 5.08 & 4.99 & 98.2 & 33.60 & 34.13 & 101.6 & 41.05 & 40.10 & 97.7 \\
\hline B-2-2 & 6.04 & 5.17 & 85.6 & 37.64 & 40.52 & 107.7 & 52.95 & 48.47 & 91.5 \\
\hline B-5-2 & 5.55 & 5.18 & 93.3 & 35.06 & 40.92 & 116.7 & 44.75 & 49.99 & 111.7 \\
\hline B-2-4 & 6.04 & 5.50 & 91.1 & 40.90 & 42.42 & 103.7 & 56.10 & 50.66 & 90.3 \\
\hline B-5-4 & 5.89 & 5.95 & 101.0 & 46.29 & 44.84 & 96.9 & 57.23 & 53.66 & 93.8 \\
\hline
\end{tabular}

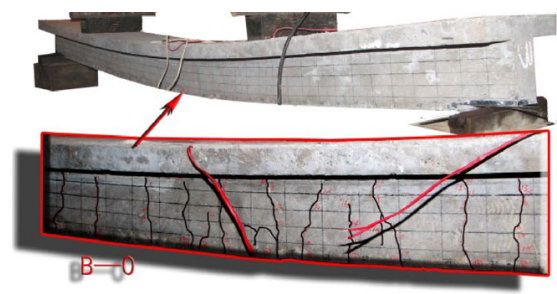

(a) B-0 (Rebar yielding and concrete crushing)

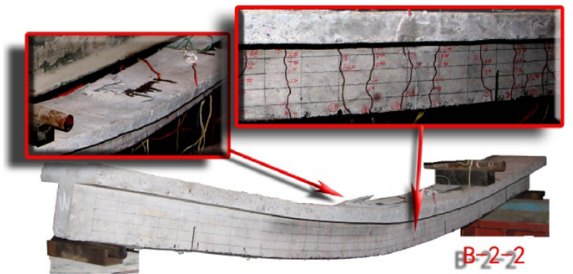

(b) B-2-2 (Steel plate yielding and concrete crushing)

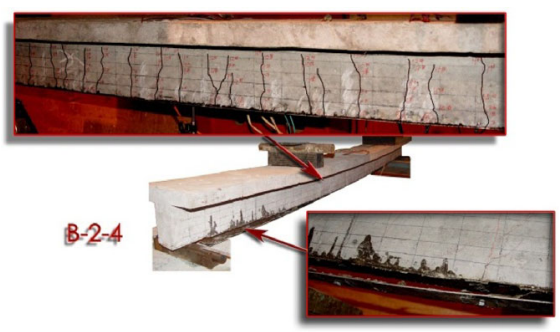

(d) B-2-4 (Bolt failure)

(c) B-5-2 (Steel plate yielding/damage and concrete crushing)

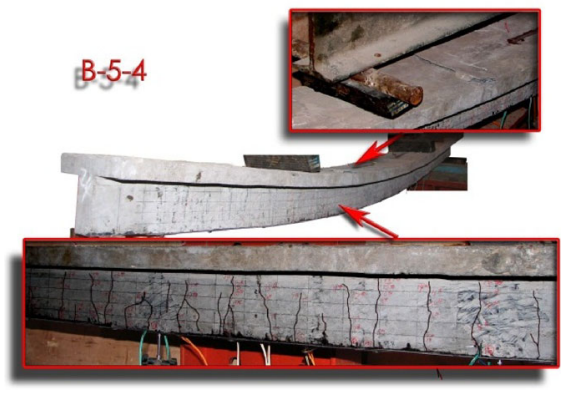

(e) B-5-4 (Steel plate yielding and concrete crushing)

Fig. 12 Experimental observations at failure.

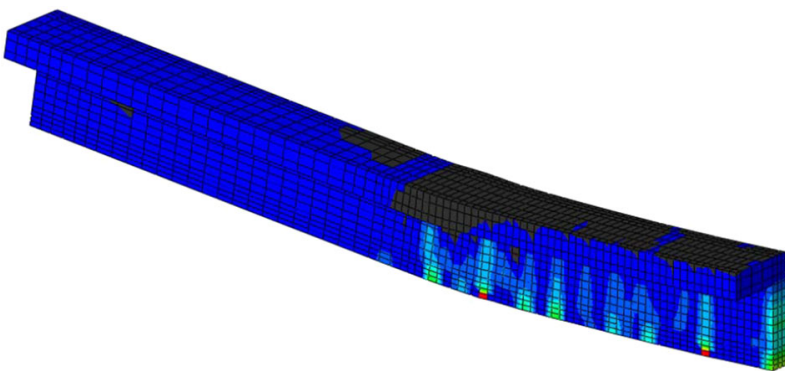

Fig. 13 Failure mode (beam B-0 shown).

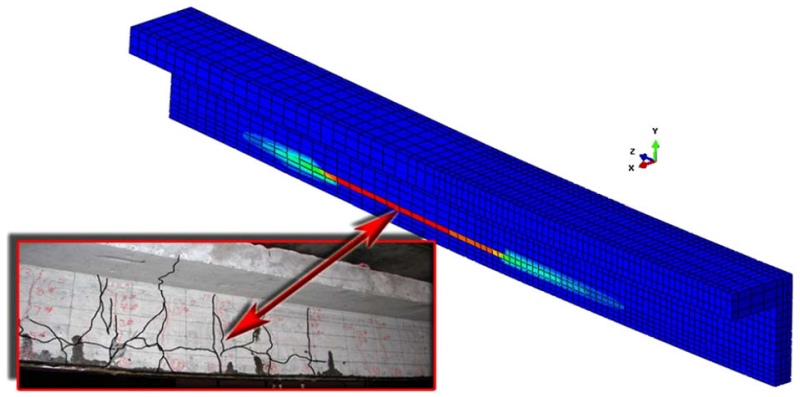

Fig. 14 Cracks along horizontal direction. 


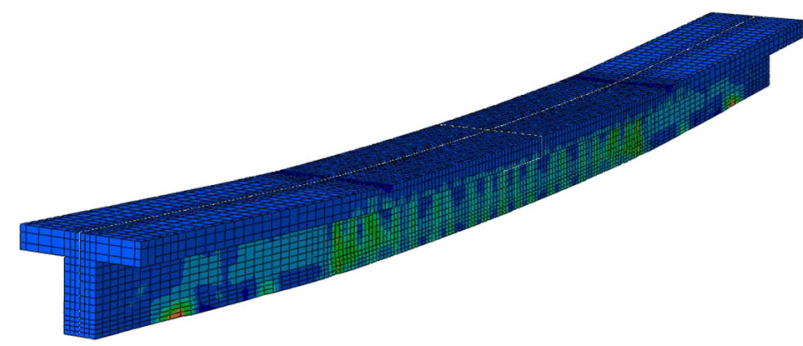

Fig. 15 Failure mode (beam B-5-4 shown).

(4) As the steel plate area increases, the force distributed in the steel plate increases; therefore the number of anchor bolts should be increased. In addition, the shear resistance of anchor bolts and the tension in the steel plate at the anchor bolt holes should be accounted in the analysis, because the anchor bolt holes could weaken the cross section.

\section{Acknowledgments}

This project was funded by Ministry of Transport of the People's Republic of China (2012 319812 100), the Shaanxi Department of Transportation (14-17 k), and the Guangdong Department of Transportation (2011-02-034).

\section{Open Access}

This article is distributed under the terms of the Creative Commons Attribution License which permits any use, distribution, and reproduction in any medium, provided the original author(s) and the source are credited.

\section{References}

ABAQUS. (2010). ABAQUS, ver. 6.9-3, 2010. Dassault Systemes Simulia Corp., Providence, RI.

Adhikary, B. B., \& Mutsuyoshi, H. (2002). Numerical simulation of steel-plate strengthened concrete beam by a nonlinear finite element method model. Construction and Building Materials, 16(5), 291-301.

Aprile, A., Spacone, E., \& Limkatanyu, S. (2001). Role of bond in RC beams strengthened with steel and FRP plates. Journal of Structural Engineering, 127(12), 1445-1452.

China, P. R. (2002). Ministry of construction. GB50010-2002. Code for design of concrete structures GB50010-2002. Beijing, China: China Architecture and Building Press.

Cicekli, U., Voyiadjis, G. Z., \& Abu Al-Rub, R. K. (2007). A plasticity and anisotropic damage model for plain concrete. International Journal of Plasticity, 23(10), 1874-1900.

Fang, Q., Huan, Y., Zhang, Y. D., \& Chen, L. (2007). Investigation into static properties of damaged plasticity model for concrete in ABAQUS. Journal of PLA University of Science and Technology (Natural Science Edition), 3, 010. (in Chinese).

Garg, A. K., \& Abolmaali, A. (2009). Finite-Element modeling and analysis of reinforced concrete box culverts. Journal of Transportation Engineering, 135(33), 121-128.

Guo, Z. H. (2001). Theory of reinforced concrete. Beijing, China: Tsinghua University Press. (in Chinese).

Jiang, J. J., Lu, X. Z., \& Ye, L. P. (2005). Finite element analysis of concrete structures. Beijing, China: Tsinghua University Press. (in Chinese).

Lee, J., \& Fenves, G. L. (1998). Plastic-damage model for cyclic loading of concrete structures. Journal of Engineering Mechanics, 124(8), 892-900.

Lubliner, J., Oliver, J., Oller, S., \& Oñate, E. (1989). A plasticdamage model for concrete. International Journal of Solids and Structures, 25(3), 299-326.

Monti, G., Renezelli, M. and Luciana, P. (2003). FRP adhesion in uncracked and cracked concrete zones. In: Proceedings of the Sixth International Symposium on FRP Reinforcement for Concrete Structures (FRPRCS-6) (pp. 183-192). Singapore.

Nakaba, K., Kanakubo, T., Furuta, T., \& Yoshizawa, H. (2001). Bond behavior between fiber-reinforced polymer laminates and concrete. ACI Structural Journal, 98(3), 359-367.

Neubauer, U. and Rostasy, F. S. (1999). Bond failure of concrete fiber reinforced polymer plates at inclined cracks-experiments and fracture mechanics model. In: Proceedings of 4th International Symposium on Fiber Reinforced Polymer Reinforcement for Reinforced Concrete Structures (pp. 369-382). MI.

Oehlers, D. J., Ali, M. M., \& Luo, W. (1998). Upgrading continuous reinforced concrete beams by gluing steel plates to their tension faces. Journal of Structural Engineering, 124(3), 224-232.

Savoia, M., Ferracuti, B. and Mazzotti, C. (2003). Nonlinear bond-slip law for FRP-concrete interface. In: Proceedings of the Sixth International Symposium on FRP Reinforcement for Concrete Structures (FRPRCS-6) (pp. 163-172). Singapore.

Transport Planning and Research Institute, Ministry of Transport, China, P. R. (1974). Highway bridge design code. Beijing, China: China Communications Press. (in Chinese).

Tuo, L., Jiang, Q., \& Chengqing, L. (2008). Application of damaged plasticity model for concrete. Structural Engineers, 24(2), 22-27 (in Chinese).

Xue, Z., Yang, L., and Yang, Z. (2010). A damage model with subsection curve of concrete and its numerical verification based on ABAQUS. In: 2010 International Conference On Computer Design And Applications (ICCDA 2010) (Vol. 5, pp. 34-37.

Zhao, S. B., Guan, J. F., \& Li, X. K. (2011). Model experiment and optimization design of the reinforced concrete structure. Beijing, China: China Water Power Press (in Chinese). 